\title{
Revisiting Student Attrition Studies: A New Conceptual Perspective
}

\author{
Helminiry Had Sabtu, Wan Shakizah Wan Mohd Noor*, Mohd Faizal Mohd Isa \\ School of Business Management, UUM College of Business, Universiti Utara Malaysia, 06010 Sintok, Kedah, Malaysia \\ *Corresponding author: shakizah@uum.edu.my
}

\begin{abstract}
This article focuses on the overview of the student attrition model as well as related theory that are pertinent to student attrition studies. It comprises an investigation into the prominent student attrition models, such as the Undergraduate Dropout Process Model presented by Spady, and Tinto's Model of Institutional Departure. Then, the focus is on the work by Bean that resulted in the Student Attrition Model, and the Pascarella produced the Conceptual Model for Research on Student-Faculty Informal Contact, as well as an exploration of attrition studies in Malaysian Higher Education. In addition, an initial conceptual research model derived from existing prominent student attrition models was proposed by the researchers for investigation in Malaysian Technical and Vocational Education and Training (TVET) student attrition studies, as well as for academic student attrition studies.
\end{abstract}

Keywords: Attrition model; attrition theory; TVET; private higher learning institutions

(C) 2016 Penerbit UTM Press. All rights reserved

\subsection{INTRODUCTION}

Mannan (2007) observed that there is developing interest and focus from the research communities from all over the world in relation to the creation the models of student withdrawal in order to give underlying reasons for the complex relations of antecedents that persuade student persistence or otherwise. In spite of this, there is minimal phenomenological research, especially by master and doctorate students on Malaysian student persistence, more specifically on student attrition in TVET institutions. By definition, attrition and retention are opposite phenomena and serve different purposes, but the heart of the relationship is that one phenomenon makes way for the other phenomenon. Bean and Metzner (1985) defined the term attrition as the failure of or missing students at an education institution, such as through withdrawal, stoppage from their study either voluntarily or involuntarily, and transferring to other similar institutions. Meanwhile, retention can be described as when a student continues to enrol in courses at the institution he or she originally registered in (Tinto, 2004).

\subsection{LITERATURE REVIEW}

Overview of Technical and Vocational Education and Training (TVET) Institutions in Malaysia

TVET is part of higher education which focuses on skills and technical competencies that has been integrated into the mainstream education system in Malaysia and has been accelerated as part of the government initiatives to become a high income nation by 2020 (Esa \& Rahman, 2014). The government through several related agencies as led by the Department of Skills Development (DSD), has been driven to promote quality of, equity, and access to education which is eventually designed to support the essential local workforce in acquiring the required skills and competencies (MohdZain, 2008; Esa \& Rahman, 2014). TVET providers are normally called Public Skills Training Institutes (institutes under the government agency) or Private Skills Training Institute (institutes under private, company, and individual ownership). Table 1 and Figure 1 show the distribution of private TVET institutions in the states throughout Malaysia.

Table 1 Number of registered private TVET institutes in Malaysia according to states (Department of Skills Development, 2015)

\begin{tabular}{lc}
\hline State & Number of Institutes \\
\hline Negeri Sembilan & 42 \\
Johor & 77 \\
Kedah & 50 \\
Kelantan & 26 \\
Labuan & 1 \\
Melaka & 38 \\
Pahang & 34 \\
Perak & 58 \\
Perlis & 6 \\
Pulau Pinang & 55 \\
\hline
\end{tabular}




\begin{tabular}{lc}
\hline Sabah & 44 \\
Sarawak & 34 \\
Selangor & 170 \\
Terengganu & 41 \\
Wilayah Persekutuan Kuala Lumpur & 81 \\
\hline
\end{tabular}

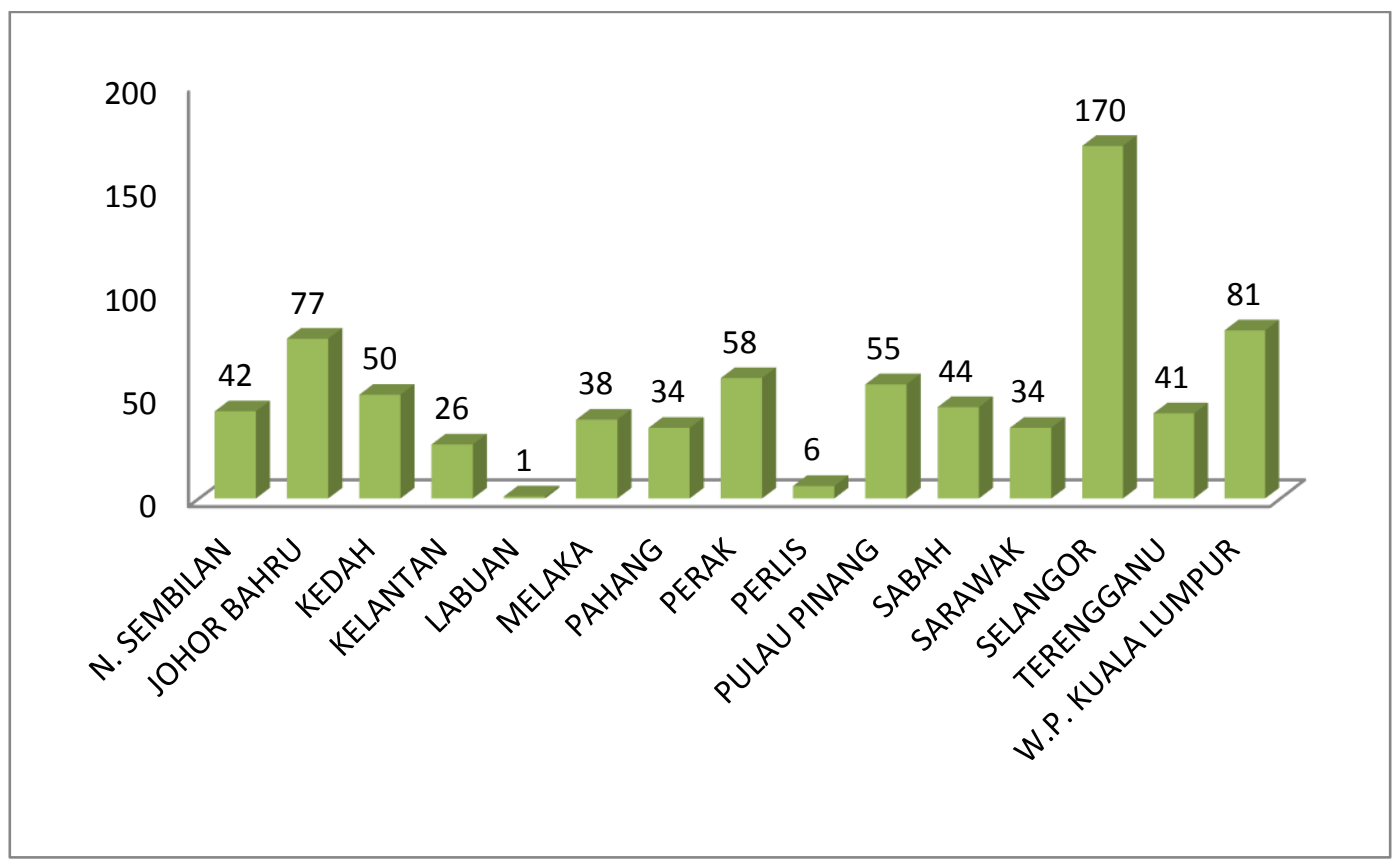

Figure 1 Number of registered private TVET institutes in Malaysian states (Department of Skills Development, 2015)

\section{Prominent Student Attrition Models}

Spady's Undergraduate Dropout Process Model is the first model reviewed in this section, followed by Tinto's Model of Institutional Departure. Next, the focus is on Bean's Student Attrition Model and Pascarella's Conceptual Model for Research on Student-Faculty Informal Contact. These famous attrition theoretical and conceptual models are considered the most established models broadly investigated by scholars in this field and keep on getting quoted and tested in numerous current empirical studies. These are also generally believed to provide the conceptual foundation for several studies and support in understanding the underlying reasons of the results in attrition studies (O'Keefe, 2013; Roos, 2012; Al-dossary, 2008). For almost four decades, the scope of student attrition has been developed virtually all over the world. The demographic characteristics of the population have encouraged researchers globally to be concerned about the most appropriate method for institutions on higher learning to be able to further efficiently cope with their student related problems, and thus expect to retain them until they finish their studies (Al-dossary, 2008; Tinto, 1982).

\section{Undergraduate Dropout Process Model}

Based on Spady's presupposition, there are various causes that contribute toward the phenomenon of student attrition in education institutions along with their action to quit and stop their studies. The main reasons highlighted by Spady in his model (Figure 2) are student family background as well as parental background, followed by their performance in primary and secondary school. Other variables include academic potential of students, normative congruence, and friendship support, as well as student capability to enhance his or her own intellectual development, grade performance in institution, social integration in his or her college or university, satisfaction with institution, and institutional commitment. Academic performance, however, also influences student satisfaction levels. Thus, the interplay between academic and social integration is central to Spady's model. 


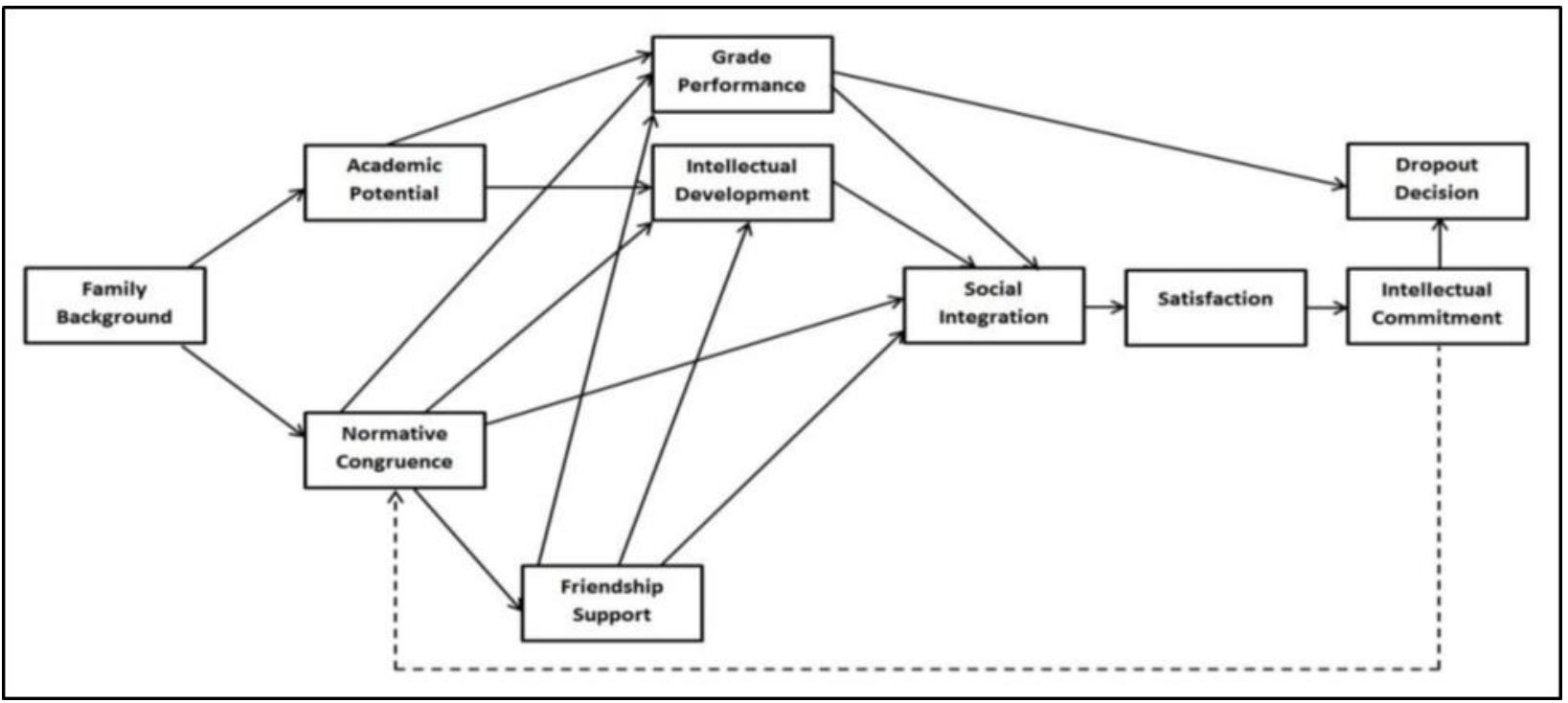

Figure 2 Spady's model of the undergraduate dropout process (Spady, 1970)

Institutional Departure Model

Institutional Departure Model (Figure 3) was created by Vincent Tinto, a notable researcher in student attrition studies. Tinto created his "model of institutional departure", which is now widely held as an exemplary framework for understanding student departure from institutions. He claimed that there are three dimensions that have an effect on student departure and retention. The three dimensions start with precollege characteristics, followed by goals and commitments, and the next stage is institutional experiences. Besides these three dimensions, Tinto identified student characteristics which help to explain student behaviour along this spectrum.

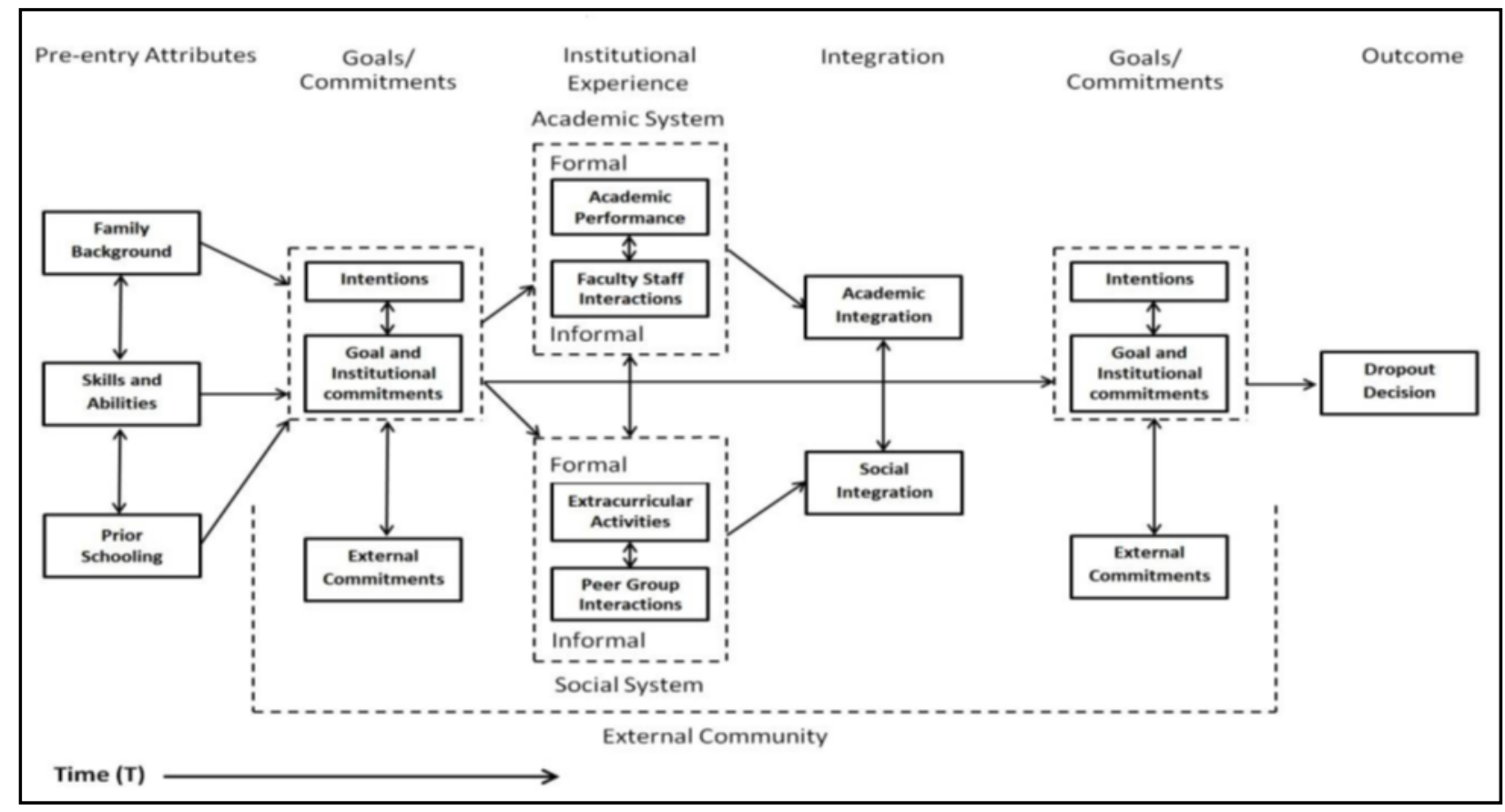

Figure 3 The institutional departure model (Tinto, 1975; Tinto, 1993)

\section{Bean's Student Attrition Model}

Bean claimed in his model (Figure 4) that the practice of student withdrawal in academic institutions is parallel to the phenomenon of employee leaving organisations that they are employed, where students and employees perhaps may leave for same or similar reasons. He 
identified that his model is similar to other established employee models related to turnover with the theory that student and employee happiness, and consequently their performance, is influenced by organisational/institutional factors. This model was constructed to classify variables influencing students' plans to leave, which is perhaps the main cause for the student attrition phenomenon, as argued by Bean. Researchers are able to modify the model for their particular purposes or contexts through improving or removing variables within these four categories.

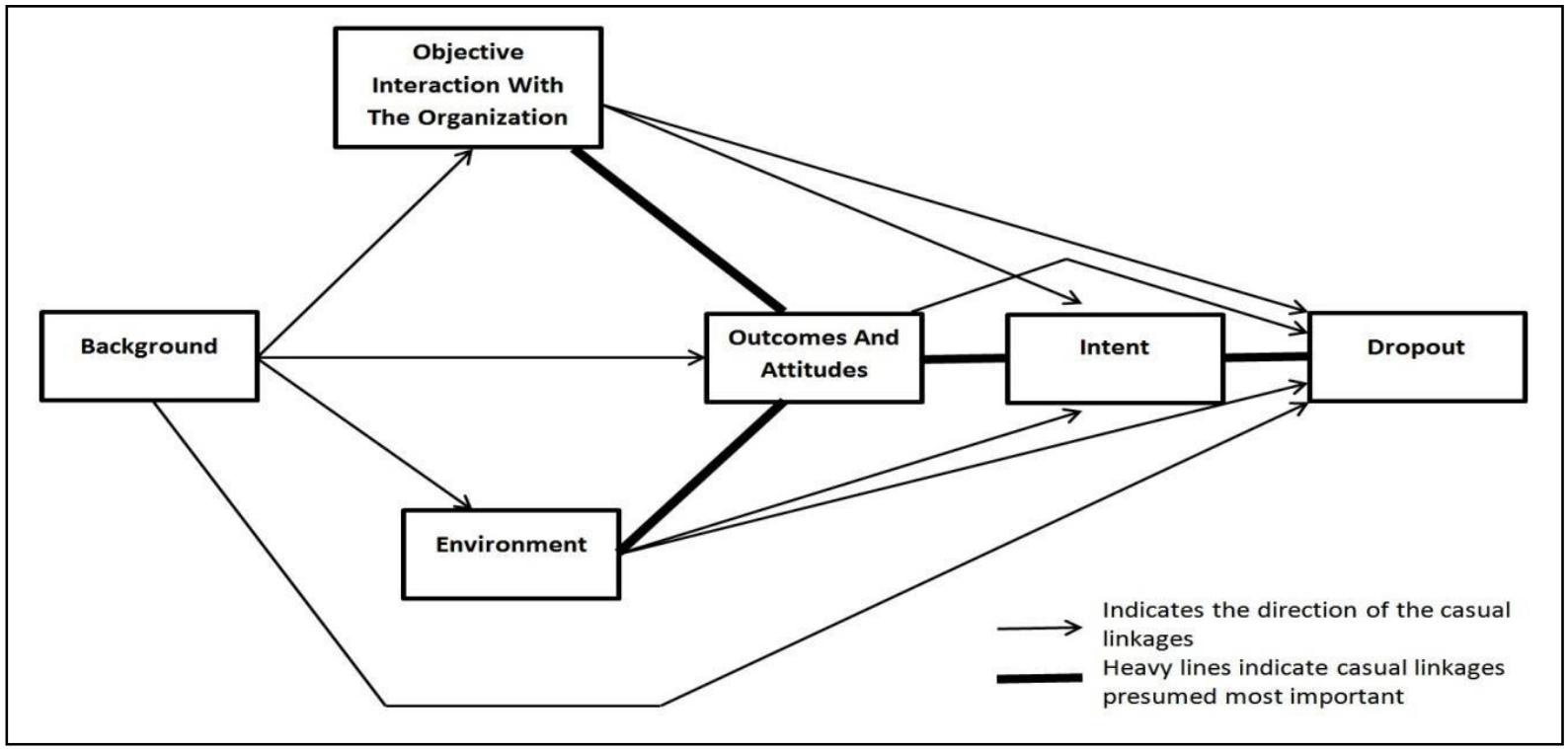

Figure 4 The student attrition model (Bean, 1980; Bean, 1982)

Pascarella's Conceptual Model for Research on Student-Faculty Informal Contact

The model from Pascarella's work (Pascarella, 1980) attempted to investigate how "to identify the distinctive encouragement of studentfaculty non-classroom contact on educational results and institutional continuity" (Figure 5). In order to achieve this, the model variables include factors relating to the institution, student background characteristics, college experiences, and informal contact with faculty. A student with background that matches with the environment tends to then stick on for admission, acceptance, and then enrolment. The college environment, altered by various characteristics of students, is affected by various individual characteristics, and consequently can impact the students' social, academic, and extracurricular experiences.

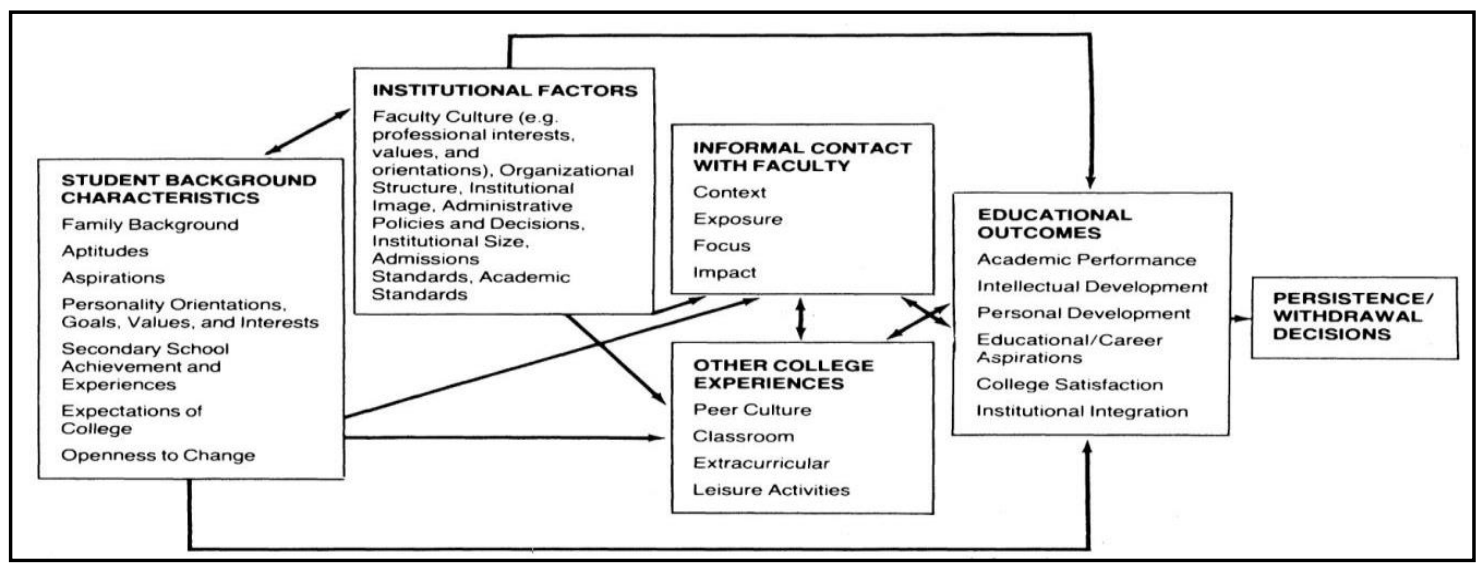

Figure 5 The student-faculty informal contact model (Pascarella, 1980)

\section{Bean and Metzner's Model of Non-traditional Student Attrition}

Traditional students can be described as students who are full-time students, aged between 18 and 24, and stay on campus, whereas nontraditional students are described as students who do not exhibit one or more of these three criteria (Bean \& Metzner, 1985). Bean and 
Metzner's (1985) model employed the four variable categories starting with background, academic, environmental, and social integration, and the outcome variables are psychological and academic. In the background category, Bean and Metzner looked specifically at gender, age, educational goals, enrolled hours, ethnicity, and high school performance.

They added three factors in addition to those in Tinto's model under academic variables; they listed grade point average (GPA) along with utility, or how useful students think their degrees will be; stress; and satisfaction, which they defined as how much the student enjoys being a student which is listed under psychological outcomes. Finally, in environmental variables, they included many items that nontraditional students grapple with, such as family responsibilities, place of employment, finance, opportunities to transfer, and outside encouragement. The interplay between all Bean and Metzner's variables is illustrated in Figure 6.

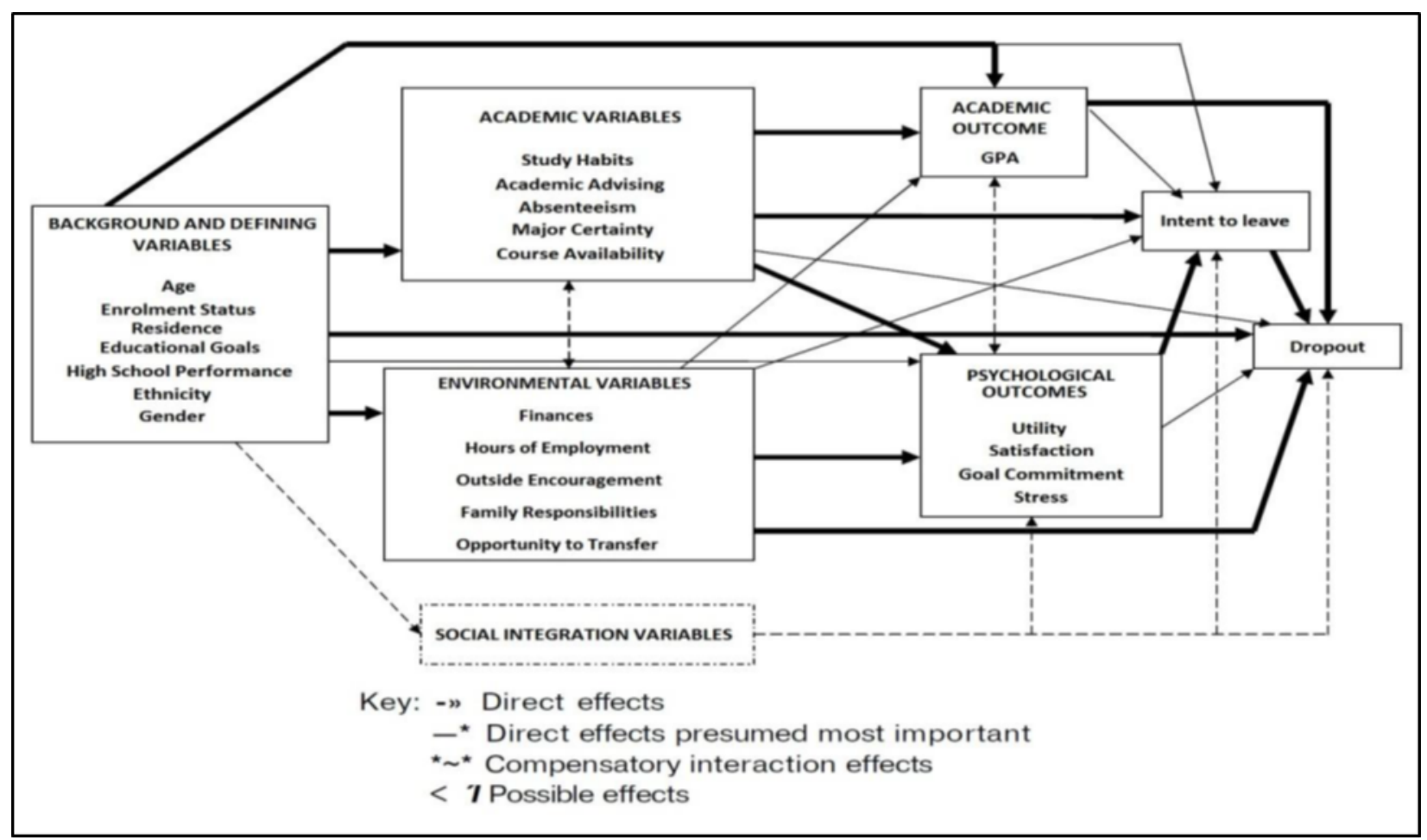

Figure 6 Conceptual model of non-traditional student attrition (Bean \& Metzner, 1985)

\section{Attrition Studies in Malaysian Higher Education}

Much student retention study efforts had been conducted in higher education institutions in different countries all over the world. However, despite the large number of studies, especially at the postgraduate levels, there is a dearth of studies related to retention and attrition conducted at colleges or universities in Malaysia.

Zainal and Affero (2011) concentrated their study on the "Attrition and Completion Issues in Postgraduate Studies for Student Development". Pertaining to this problem, two methods were recommended. The first approach is to give varied data and encourage at the assorted phases of improvement in graduate studies, to request a general information guide facilitating the graduate process, and to provide several information foundations and back up structures available to assist in the first improvement phase. In addition to research methodology, communicating periods on the use of the library, scientific writing in general along with the writing of a proposal, are also recommended in the first approach. This method is capable of fulfilling the wishes of students and thus further these students along the progression line with more focus being given on data collecting, valuation, assembling a thesis or dissertation, organise, analysis, and the publication of study results.

Meanwhile, Hematram, Yusoff, and Tan (2012) estimated the attrition rate and identified common characteristics of medical students who withdrew from an undergraduate medical programme. This study retrospectively analysed records of students who withdrew from a medical programme from 10 student cohorts between 2002 and 2007 in the pre-clinical phase in the International Medical University (IMU), Kuala Lumpur, Malaysia. Data on student gender, pre-university entry, banding, and English prerequisite in Malaysian University English Test (MUET) or International English Language Testing System (IELTS) were studied and compared with all students entering the university during the same study period. The study found that attrition was higher among male students. Other studies had also shown that male students are more likely to withdraw from a university course than female students (Fogelman \& Vander Zwagg, 1981). Gupta (1991) reported a male to female attrition rate of 1.5:1. The higher attrition among male students may be related to study habits, personal problems, or coping skills.

Meanwhile in another vein, Govindarajo and Kumar (2012) published work titled "How to Combat Attrition? Case Study on a Malaysian Educational Institution". These researchers pointed out few factors for consideration, namely related to the "persuasive factors" that are precedent to the present attrition phenomenon at the universities. Some of the persuasive factors include unattractive scholarship offer, negative perception on home grown programme awards, personal finance problems, and difficulty of passing exam papers. Other factors are 
environment, culture, food, weather, tuition fees increase, dismissal for poor academic performance, language difficulties, personal behaviour, learning style, loans, and issues related to certificates.

Next, the degree research project by William, Khoon, Xin, Shen, and Yuan (2013) is reviewed. They explored and focused on the causes that may affect attrition and retention of undergraduate students to go on for postgraduate studies or withdraw at their current institution. Consequently, results showed the important factors that influence student choice and action to continue their postgraduate studies at the present institution are related to institutional aspects such as quality of teaching by lecturers and college or university environment, students' social contacts at institutions, together with financial aids.

\subsection{THEORETICAL FRAMEWORK}

The purpose of the initial conceptual research model was to address some key factors or variables for study that may possibly have an effect on student attrition. This model narrows the focus of the study and provides guidelines for the research topic of student retention. This researcher believes and identified three variables to be significant in influencing student attrition in Malaysian TVET Institution as well as for academic institutions. These variables are student background characteristics, institutional factors, and environmental factors. They were all derived from the existing established student attrition models and an in depth literature review. New researchers in Malaysian student attrition studies can apply this model as a new research direction as well as implement this model so that it can be explored in the future. Figure 7 is the conceptual research model that was derived from the existing prominent student attrition models and literature review.

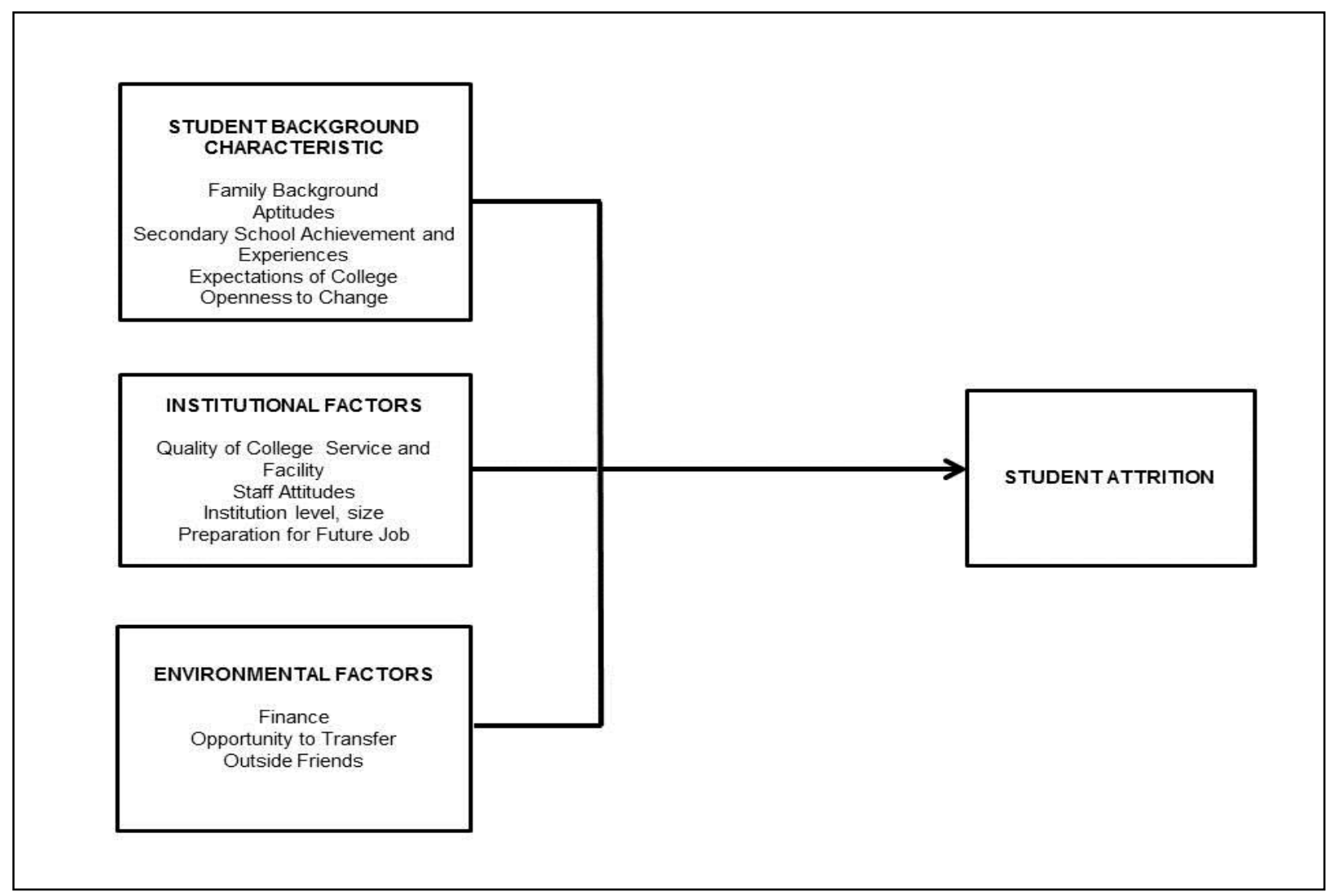

Figure 7 The initial conceptual research model

\subsection{CONCLUSION}

Most institutions face huge challenges on how to combat attrition and try the best approach to improve institutional rates of retention and completion. This article presented an overview of some of the areas of student attrition literature that are linked to the application of the present research. This included an overview of the theoretical models and their different types and categories. Moreover, the paper reviewed the most cited student attrition models of the last four decades, since the emergence of attrition and retention studies. The literature of student attrition and retention of the last four decades facilitates a better understanding of the phenomenon and provides a comprehensive set of factors shown often to affect student withdrawal decisions.

Moreover from the review of literature and publication related to the retention and attrition phenomenon, it was observed that the results of studies performed in the Malaysian education context were similar and thus not very different from similar studies performed elsewhere in the world. It was concluded that institutional factors formed the general theme throughout all these studies, both in the Malaysian and 
international contexts. This category of factors consists of factors mainly relating to students' interaction and experience with the administration of their academic institution, including the registration, admission, and disciplinary policies and rules, as well as the availability and quality of student facilities. Additionally, initial review had also uncovered other factors akin to the Malaysian education context, which include personal, academic, and social categories. Another potential factor that was uncovered was students' poor academic abilities, however, this factor is not related to voluntary withdrawal from the education system, but rather more closely related to academic dismissal, which has been deemed to be beyond the scope of most attrition models, including this study.

\section{References}

Al-dossary, S. A. (2008). A Study of the Factors Affecting Student Retention at King Saud University, Saudi Arabia. Structural Equation Modelling and Qualitative Methods.

Bean, J. (1980). Dropouts and Turnover: The Synthesis and Test of a Causal Model of Student Attrition. Research in Higher Education, 12(2), 155-187.

Bean, J. (1982). Conceptual Models of Student Attrition: How Theory can help the Institutional Researcher. New Directions for Institutional Research, 1982(36), 1733.

Bean, J., \& Metzner, B. (1985). A Conceptual Model of Nontraditional Undergraduate Student Attrition. Review of Educational Research, 55(4), 485-540. doi: $10.3102 / 00346543055004485$

Department of Skills Development (2015). Pusat Bertauliah Mengikut Negeri. Retrieved 13/7/2016 from http://www.dsd.gov.my/apps.dsd.gov.my/webjpk2/ JPK_program_list/carian_negeri.php

Esa, A., \& Rahman, J. A. (2014). TVET and Strategies Helping Student Providers into Market. Journal of Education and Human Development, 3(2), 743-751.

Fogelman, B. Y. S., Vander Zwagg, R. (1981). Demographic, Situational, and Scholastic Factors in Medical School Attrition. Southern Medical Journal, 74, 602-606.

Govindarajo, N. S., \& Kumar, M. D. (2012). How to Combat Attrition? Case Study on a Malaysian Educational Institution. International Journal of Business and Behavioural Sciences, 2(8), 24-33.

Gupta, G. C. (1991). Student Attrition: A Challenge for Allied Health Education Programmes. Journal of American Medical Association, $266,963-967$.

Hematram, Y., Yusoff, N., \& Tan, K. L. (2012). Attrition of Medical Students in International Medical University - 2002 to 2007. South East Asian Journal of Medical Education, 6(1), 42-44.

Mannan, M. A. (2007). Student Attrition and Academic and Social Integration. Application of Tinto's model at the University of Papua New Guinea. Higher Education, 53(2), 147-165

MohdZain, Z. (2008). TVET in Malaysia. Retrieved 16/8/2016 from http://dspace.unimap.edu.my/dspace/bitstreamll23456789/7186/1/TVET\%20in\% 20Malaysia.pdf

O'Keefe, P. (2013). A Sense of Belonging. Improving Student Retention. College Student Journal, 47, 195-199.

Pascarella, E. T. (1980). Student-Faculty Informal Contact and College Outcomes. Review of Educational Research, $50(4), 545$.

Roos, R. (2012). Relationship between First-Year Student Retention, Noncognitive Risk Factors, and Student Advising. Unpublished Thesis. Utah State University. Retrieved 27/8/2016 from http://digitalcommons.usu.edu/cgi/viewcontent.cgi?article=2156\&context=etd

Spady, W. (1970). Dropouts from Higher Education: An Interdisciplinary Review and Synthesis. Interchange, 1(1), 64-85. DOI: 10.1007/bf02214313.

Tinto, V. (1975). Dropout from Higher Education: A Theoretical Synthesis of Recent Research. Review of Educational Research, 45(1), 89-125.

Tinto, V. (1982). Limits of Theory and Practice in Student Attrition. The Journal of Higher Education, 53(6), 687-700

Tinto, V. (1993). Leaving College: Rethinking the Causes and Cures of Student Attrition (2nd ed.). Chicago, IL: University of Chicago Press

Tinto, V. (2004). Student Retention and Graduation: Facing the Truth, Living with the Consequences. Occasional Paper 1. Pell Institute for the Study of Opportunity in Higher Education.

William, C., Khoon, C. S., Xin, E. L., Shen, L. K., \& Yuan, T. C. (2013). Retention of Undergraduate Students at a Private University in Malaysia. Unpublished Bachelor Degree Project Report. Faculty of Business and Finance, Department of Marketing, Universiti Tunku Abdul Rahman.

Zainal, N., \& Affero, C. (2011). Attrition and Completion Issues in Postgraduate Studies for Student Development. Social Sciences, 1(1), 15-29. 